\title{
The clover root weevil in northern pastures: on-farm observations of its impact on white clover
}

\author{
J.P.J. EERENS ${ }^{1}$, B. WILLOUGHBY ${ }^{1}$, F. KETTLEWELL ${ }^{1}$, S. HARDWICK ${ }^{1}$ and S. BAY ${ }^{2}$ \\ ${ }^{1}$ AgResearch, Ruakura Research Centre, Private Bag 3123, Hamilton, New Zealand \\ ${ }^{2}$ Manawaru Road, RD 1, Te Aroha, Waikato, New Zealand
}

\begin{abstract}
The clover root weevil (CRW) (Sitona lepidus) has had, over the last two years, a major impact on pastoral farming in the greater Waikato area. Research into CRW biology, damage profile and financial impact is continuing and far from complete. A survey of farms in the affected areas in 1997/98 yielded a large volume of on-farm observations. A survey of the impact of CRW on clover on a single farm produced data that estimated the cost of CRW to this farming operation. These anecdotal findings are combined with initial results from a glasshouse experiment. Damage by CRW tended to be less on lighter (ash and pumice) soils than on heavier, more water-retentive (peat and clay) soils. Drought reduced CRW egg survival and the ratio of first instar larvae to number of eggs hatched. Damage was greater under hard than lax defoliation regimes and increased with increasing rates of mineral nitrogen application. Red clover appeared to be less affected by CRW than white clover. The general picture suggested that the level of stress placed on the clover plant played a major role in the impact of CRW on those clover plants: the higher the stress levels the greater the impact of CRW.
\end{abstract}

Keywords: clover root weevil, farm survey, pasture pest, Sitona lepidus, Trifolium repens, white clover

\section{Introduction}

The clover root weevil (CRW) (Sitona lepidus) was first identified in New Zealand in early 1996 (Barratt et al. 1996). An initial survey of its distribution found that there were two distinct areas of infection, one centred around Tauranga, and one around Auckland (Barker et al. 1996). At the time of discovery, the area infested by CRW was over 200000 ha, which made effective containment and eradication of the pest economically and environmentally unviable. Adult CRW are surface dwellers, depositing their eggs on the soil surface or on plant material. Larvae and pupae are found near to and in the roots and nodules of clover plants. Both the adults and larvae are present throughout the year, complicating potential management strategies.
Farmers and researchers, over the past two years, have observed considerable variation in the level of damage to white clover (Trifolium repens) in the CRWinfested area. On a single farm, pastures could be virtually devoid of white clover while strong healthy white clover plants were growing along ditches, raceways and in lawns. This could be partly owing to variable CRW population densities between sites, seasons and years, but the evidence, albeit circumstantial, indicated that CRW could not be held entirely to blame. Within paddocks there was significantly more white clover in ungrazed/dung patches than elsewhere in the paddock (J.P.J. Eerens, unpublished data), which indicated that grazing animals contributed to some degree to the absence of white clover.

$\mathrm{CRW}$, present in pastures throughout Europe and North America, is not viewed there as a serious economic pest. A consequence is that there is little overseas research on CRW applicable to managing this pest in the New Zealand situation. The New Zealand farming situation is unique in combining a dependence on white clover with all-year-round grass farming. Also, in its countries of origin, the CRW is competing for resources (e.g., egg laying sites and food) with other weevil pests, and it is likely that there are a number of other population regulatory factors acting (e.g., predation and disease). However, in New Zealand the CRW is currently unchecked, in the absence of serious competition and predators.

The focus of the current research effort is split into understanding the pest and developing integrated pest management strategies. Understanding CRW biology is essential to identify vulnerable points in its life cycle, which can then be exploited to manage the pest. Components of the integrated pest management options looked at include, pasture management that minimises the impact of CRW, identifying resistant/tolerant clover germplasm for cultivar development and biological control options.

A questionnaire was designed to quantify farmer perceptions of some of the impacts of CRW. Of particular interest were the perceived CRW damage levels to white clover in combination with farm type, soil type, availability of irrigation, age of pastures and cultivars used. This paper presents selected points of interest from the questionnaire data, substantiated by initial results from a glasshouse experiment and a farmer 
estimation of the economic impact of CRW in a specific instance.

\section{Method}

\section{Regional survey}

A questionnaire on CRW was distributed to farmers in 1997 and the information from 206 replies referring to 566 paddocks was collated. Replies were received both from areas that were infested by CRW and areas free of CRW. The data presented here include only the questionnaire responses from CRW-infested areas (141 replies covering 357 paddocks). The impact of CRW assessed by comparing CRW-infested and CRW-free areas has been reported elsewhere (Willoughby \& Kettlewell 1998).

The questionnaire asked about the level of CRW damage (a key was included), the age of the pasture, fertiliser application regime (especially nitrogen application), visual assessment of clover content, soil type, clover and grass species and cultivars used, and stocking rate. Soil types were grouped into four classes, based on their capacity to retain water. Data were analysed using Genstat analysis of variance.

\section{Farm survey}

A survey of 69 paddocks was carried out on a dairy farm near Te Aroha. The local consultant surveyed the pastures and visually assessed them for clover content, CRW damage levels and standing herbage levels. We acknowledge that the observations represent a single point in time, but this is the first such survey.

\section{Glasshouse experiment}

A glasshouse experiment was carried out in crates, measuring $360 \mathrm{~mm}$ (deep) by $330 \times$ $330 \mathrm{~mm}$, at Ruakura Agricultural Research Centre in the spring and summer of 1997/98. The crates were split into two equal compartments, each filled with $250 \mathrm{~mm}$ subsoil, compacted to field density, on top of which $100 \mathrm{~mm}$ compacted topsoil was placed. A total of 128 crates were used and treatments included: CRW (present or absent); topsoil type (peat or mineral); moisture (dry or moist); Olsen P levels (30 or 15); nitrogen (0 or $200 \mathrm{~kg} / \mathrm{ha}$ added); white clover cultivar (Prop or Challenge); cutting regime (hard or lax); and plant type (seedling or stolon tip). Each of the 256 treatments occupied half a compartment and was replicated twice.

Plants were grown for 14 weeks before treatments were applied. CRW eggs were washed onto the appropriate treatments at a density of $4000 \mathrm{eggs} / \mathrm{m}^{2}$. Plants were trimmed to $30 \mathrm{~mm}$ at the start of the experiment and every 3 weeks after that. A final harvest was carried out 8 weeks after inoculation with CRW when soil was sieved to collect CRW larvae and all clover plant material. Data were analysed as a split plot design, with a full set of 64 treatments within each weevil $\mathrm{x}$ moisture treatment and using the actual number of CRW larvae retrieved at the end of the experiment as a co-variate.

\section{Results}

\section{Regional survey}

The area from which replies were received was extensive, from Otorohanga to Whangarei, from west Waikato to Whakatane. Virtually all the information came from dairy farms, which restricts the interpretation of the results. Most (76\%) paddocks were at least 5 years old, and data for other factors were similarly skewed, which made analysis of the data difficult. Analysis was further complicated by an inability to quantify a number of factors, such as the pasture management skill level, the presence of other pests, the pasture renovation method used, use of a break crop (involving full cultivation) or grass to grass (under- or oversowing), and whether a conservation crop had been taken.

Figure 1 Relationship between stocking rate and CRW foliar damage index when (a) $>100 \mathrm{~kg}$ nitrogen/ha is applied (damage $=-28.9+$ $11.9^{*}$ stocking rate, $r^{2}=0.472, P<0.001$ ) or (b) no nitrogen is applied (damage $=38.1-10.2^{*}$ stocking rate, $r^{2}=0.601, P<0.01$ ).

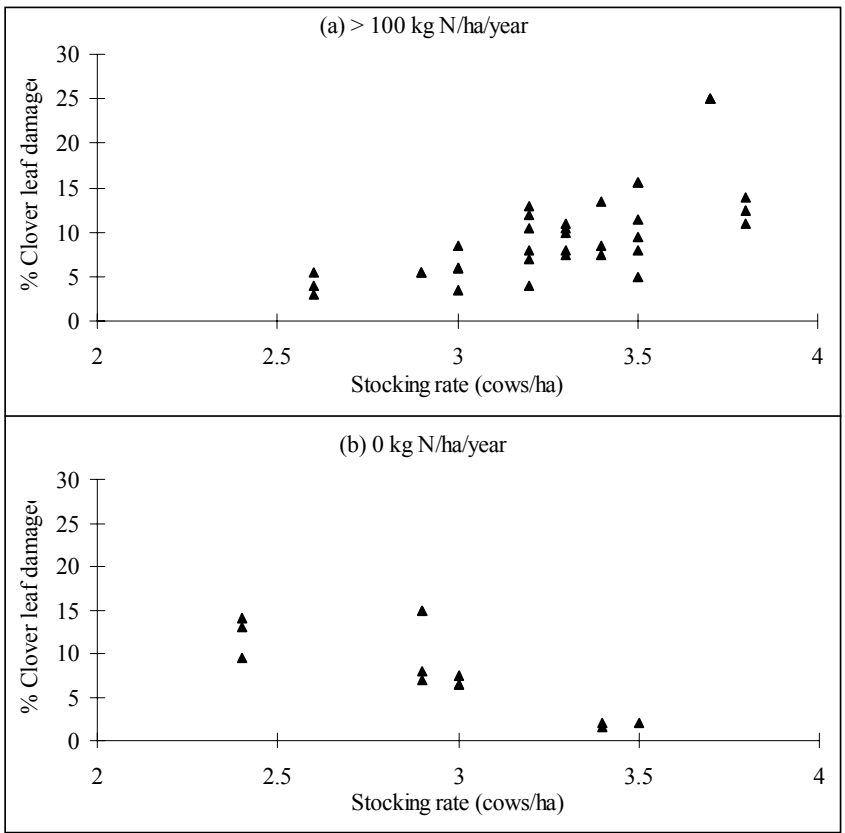


There appeared to be an interaction between stocking rate and the level of nitrogen fertiliser applied on CRW foliar damage. At high levels of nitrogen application $(>100 \mathrm{~kg} / \mathrm{ha})$ there was a positive interaction $\left(\mathrm{r}^{2}=0.472\right)$ between stocking rate and clover damage (Figure 1a), while a negative interaction $\left(\mathrm{r}^{2}=0.601\right)$ between stocking rate and damage was observed when no nitrogen was applied (Figure 1b). At intermediate levels of nitrogen application there were no obvious interactions. Another trend was for CRW foliar damage to clover to be worst on soils with a high water holding capacity.

\section{Single farm survey}

The visual assessment information in Table 1 demonstrates that the clover content of relatively young pastures was well in excess $(\mathrm{P}<0.001)$ of that of older pastures. Clover content was higher $(\mathrm{P}<0.05)$ in irrigated pastures while $\mathrm{CRW}$ foliar damage was less $(\mathrm{P}<0.01)$ in old irrigated pastures than in old non-irrigated pastures, with no irrigation effects on CRW damage in young pastures.

Table 1 Average scores over 69 paddocks of a single farm, assessed for clover content ( $\%$ of total DM), CRW damage score ( $\%$ leaf area damaged by CRW), and pasture cover (kg DM/ha).

\begin{tabular}{llccc}
\hline & & Clover\% & $\begin{array}{c}\text { CRW } \\
\text { damage } \\
\text { score }\end{array}$ & $\begin{array}{c}\text { Pasture } \\
\text { cover }\end{array}$ \\
\hline Non-irrigated & Cultivated in last 6-8 years & 17.8 & 2 & 1810 \\
& Not cultivated in last 6-8 years & 4.9 & 12.6 & 1820 \\
\multirow{2}{*}{ Irrigated } & Cultivated in last 6-8 years & 25.8 & 1.7 & 2100 \\
& Not cultivated in last 6-8 years & 8.8 & 3.8 & 2035 \\
\multirow{2}{*}{ LSD $_{5 \%}$} & & 6.2 & 3.9 & 395 \\
\hline
\end{tabular}

Table 2 Average total (of two cuts) shoot yields (g/plot) of Weevil ${ }^{*}$ Moisture ${ }^{*}$ Cultivar ${ }^{*}$ Cutting treatments applied to white clover in a glasshouse experiment $\left(\mathrm{LSD}_{5} \%\right.$ interaction 0.237).

\begin{tabular}{llccccc}
\hline \multirow{2}{*}{ Moisture } & & \multicolumn{3}{c}{ Challenge } & \multicolumn{3}{c}{-- Prop -- } & Average \\
\hline \multirow{2}{*}{ Dry } & Cutting & Hard & Lax & Hard & Lax & \\
Wet & No-weevil & 1.23 & 2.15 & 1.21 & 1.61 & 1.55 \\
& Weevil & 1.30 & 1.73 & 0.87 & 1.75 & 1.41 \\
& No-weevil & 1.79 & 3.04 & 1.70 & 2.22 & 2.19 \\
& Weevil & 1.26 & 2.57 & 1.12 & 2.41 & 1.84 \\
& Average & 1.40 & 2.37 & 1.22 & 2.00 & \\
\hline
\end{tabular}

\section{Discussion}

The regional and farmer surveys were both interpreted on the basis of CRW damage as assessed from adult foliar feeding, while the glasshouse experiment assessed the effect of root-feeding CRW larvae. CRW foliar damage, while a good indicator of CRW presence, may not be all that critical to clover plants. Clover has been bred to be defoliated, although not continuously all year round as adult CRW tend to do. It is the larval damage done to the clover root system, especially before a dry spell, which plays a critical role in restricting clover survival, which needs to be investigated.

The regional survey, on-farm survey and the glasshouse experiment all indicate that the level of soil moisture is a major limiting factor not only for the level of clover productivity, but also for CRW population density. This confounding effect makes it difficult to determine the influence of either CRW or drought on

\section{Glasshouse experiment}

Soil moisture significantly $(\mathrm{P}<0.001)$ influenced the number of CRW larvae retrieved at the end of the experiment, the number retrieved being on average 11.4/ plot for the moist and $0.95 /$ plot for the droughted treatment. There were no differences in weevil numbers between the cultivars.

Shoot yields were $12 \%$ lower $(\mathrm{P}<0.05)$ in the plots to which weevils were added (Table 2$)$. The presence of weevil depressed shoot yield more $(\mathrm{P}<0.001)$ under a hard then under a lax defoliation regime (by $22 \%$ and $6 \%$ respectively), more $(\mathrm{P}<0.001)$ under moist then under dry conditions (15\% and $9 \%$, respectively) and more $(\mathrm{P}<0.001)$ for Challenge than for Prop $(16 \%$ and $9 \%$, respectively). For the last two comparisons, the average yields of moist and Challenge treatments were higher in the presence of weevil than the weevil-free dry and Prop treatments respectively. this clover suppression.

The most important general trend was that when growing conditions were more favourable, clover productivity was higher irrespective of the presence of CRW. Biotic stresses on white clover tended to be synergistic; when the plant was stressed by hard defoliation, the damage expression in the presence of CRW was greater than when the plants were not stressed under lax defoliation. Weevil damage may be less under drought conditions than under moist conditions (Table 1), as a result of very low numbers of larvae developing under dry conditions, but drought by itself depressed clover productivity relative to moist conditions. Farmers may have little control (if no irrigation is available) over soil moisture levels, but they can control defoliation intensity, stocking rate and the amount of nitrogen fertiliser applied. Woodfield \& Caradus (1996) related clover persistence to environ- 
mental and pasture management factors and described the impact of actions by farmers on the white clover plant. Healthy clover plants are less likely to be affected by CRW infestation than plants already struggling to survive.

The observation of more CRW damage and less clover in older paddocks may be the result of differences in the white clover cultivars used, but could also be owing to differences in plant structure between older and younger plants. White clover plants initially form a tap-root which dies off, depending on the conditions, in the second year, after which the plant exclusively depends on fibrous roots. It is postulated that larvae do more damage to fibrous roots than to the lignified taproots. This could explain farmer observations that red clover (T. pratense), which maintains it tap-root for the life of the plant, is more tolerant to CRW than white clover. It is acknowledged that a variety of other factors could be responsible for this observation.

\section{Concluding remarks}

It is too early to reach firm conclusions on the interactions between environment and CRW, but some trends are becoming clear. Low soil moisture levels appears to reduce the population density of CRW larvae in the soil. The same factor also suppresses white clover growth and therefore, may not be efficient as a management tool. Defoliation pressure appears to be a management option that does have some influence on the level of CRW damage. It is also encouraging to see that within white clover germplasm there is variation in the response to $\mathrm{CRW}$ infestation.
The costs of CRW are estimated at $\$ 50 / \mathrm{ha} /$ year (S. Bay, unpublished data) for the extra nitrogen fertiliser required to maintain pasture production levels. Other costs are a reduction in production of saleable product (e.g., milk, meat, wool) per kg of forage, as the feeding value of pastures reduces as clover content reduces (Eerens et al. 1997). A cost saving associated with CRW may be a lower requirement for bloat control (S. Bay, unpublished data).

\section{REFERENCES}

Barker, G.M.; Addison, P.J.; Firth, A.C.; Barratt, B.I.P. 1996. Sitona lepidus Gyllenhal newly established in New Zealand: Assessment of distribution in the North Island. Proceedings of the New Zealand Plant Protection Conference 49: 266-269.

Barratt, B.I.P.; Barker, G.M.; Addison, P.J. 1996. Sitona lepidus Gyllenhal (Coleoptera: Curculionidae), a potential clover pest new to New Zealand. New Zealand entomologist 19: 23-30.

Eerens, J.P.J.; Miller, K.B.; Lucas, R.J.; White, J.G.H.; Easton, H.S. 1997. White clover versus nitrogen fertiliser 2. Sheep production. Proceeding of the XVIII International Grassland Congress, Session 22: 5354.

Willoughby, B.; Kettlewell, F. 1998. Farmer observations on the impact of the clover root weevil (Sitona lepidus) on Waikato farms. Proceedings of the New Zealand Plant Protection Conference 51: 268.

Woodfield, D.R.; Caradus, J.R. 1996. Factors affecting white clover persistence in New Zealand pastures. Proceedings of the New Zealand Grassland Association 58: 229-235. 